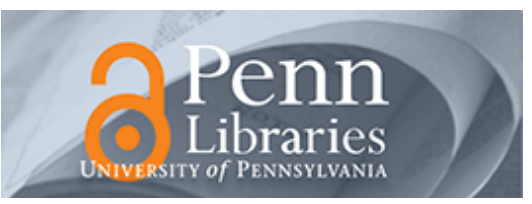

University of Pennsylvania ScholarlyCommons

7-14-2009

\title{
Defect-Mediated Adsorption of Methanol and Carbon Dioxide on $\mathrm{BaTiO}_{3}(001)$
}

\author{
J. Garra \\ University of Pennsylvania \\ John M. Vohs \\ University of Pennsylvania, vohs@seas.upenn.edu \\ Dawn A. Bonnell \\ University of Pennsylvania, BONNELL@SEAS.UPENN.EDU
}

Follow this and additional works at: https://repository.upenn.edu/mse_papers

Part of the Materials Science and Engineering Commons

\section{Recommended Citation}

Garra, J., Vohs, J. M., \& Bonnell, D. A. (2009). Defect-Mediated Adsorption of Methanol and Carbon Dioxide on $\mathrm{BaTiO}_{3}(001)$. Retrieved from https://repository.upenn.edu/mse_papers/195

Suggested Citation:

Garra, J., Vohs, J.M. and Bonnell, D.A. (2009). "Defect-mediated adsorption of methanol and carbon dioxide on $\mathrm{BaTiO}_{3}(001)$." Journal of Vacuum Science and Technology A. Vol. 27(6). pp. L13 - 17.

(c) 2009 American Vacuum Society. This article may be downloaded for personal use only. Any other use requires prior permission of the author and the American Vacuum Society. The following article appeared in Journal of Vacuum Science and Technology and may be found at http://dx.doi.org/10.1116/1/3168563.

This paper is posted at ScholarlyCommons. https://repository.upenn.edu/mse_papers/195

For more information, please contact repository@pobox.upenn.edu. 


\title{
Defect-Mediated Adsorption of Methanol and Carbon Dioxide on $\mathrm{BaTiO}_{3}(001)$
}

\author{
Abstract \\ The surface chemistry of single crystal barium titanate $\left(\mathrm{BaTiO}_{3}\right)$ has been studied using temperature \\ programmed desorption (TPD). TPD measurements were performed with several probe molecules, \\ including methanol and carbon dioxide. The role of oxygen vacancies in the adsorption and reaction of \\ these molecules was examined by annealing the crystal under oxidizing or reducing conditions prior to \\ performing TPD. It is shown that the adsorption and reaction of methanol and carbon dioxide are \\ enhanced on $\mathrm{BaTiO}_{3}(001)$ by annealing the crystal under reducing conditions. \\ Disciplines \\ Engineering | Materials Science and Engineering

\section{Comments} \\ Suggested Citation: \\ Garra, J., Vohs, J.M. and Bonnell, D.A. (2009). "Defect-mediated adsorption of methanol and carbon \\ dioxide on $\mathrm{BaTiO}_{3}(001)$." Journal of Vacuum Science and Technology A. Vol. 27(6). pp. L13 - 17. \\ (c) 2009 American Vacuum Society. This article may be downloaded for personal use only. Any other use \\ requires prior permission of the author and the American Vacuum Society. The following article appeared \\ in Journal of Vacuum Science and Technology and may be found at http://dx.doi.org/10.1116/1/ \\ 3168563.
}




\title{
LETTERS
}

\section{Defect-mediated adsorption of methanol and carbon dioxide on $\mathrm{BaTiO}_{3}(001)$}

\author{
J. Garra \\ Department of Materials Science and Engineering, University of Pennsylvania, Philadelphia, \\ Pennsylvania 19104 \\ J. M. Vohs \\ Department of Chemical and Biomolecular Engineering, University of Pennsylvania, Philadelphia, \\ Pennsylvania 19104 \\ D. A. Bonnella) \\ Department of Materials Science and Engineering, University of Pennsylvania, Philadelphia, \\ Pennsylvania 19104
}

(Received 20 April 2009; accepted 8 June 2009; published 14 July 2009)

\begin{abstract}
The surface chemistry of single crystal barium titanate $\left(\mathrm{BaTiO}_{3}\right)$ has been studied using temperature programmed desorption (TPD). TPD measurements were performed with several probe molecules, including methanol and carbon dioxide. The role of oxygen vacancies in the adsorption and reaction of these molecules was examined by annealing the crystal under oxidizing or reducing conditions prior to performing TPD. It is shown that the adsorption and reaction of methanol and carbon dioxide are enhanced on $\mathrm{BaTiO}_{3}(001)$ by annealing the crystal under reducing conditions. (C) 2009 American Vacuum Society. [DOI: 10.1116/1.3168563]
\end{abstract}

\section{INTRODUCTION}

Ferroelectric materials naturally exhibit a spontaneous polarization that can be reversed under the influence of an applied electric field. The surface behavior of ferroelectric materials is currently of significant interest due in part to proposals for new approaches to catalysis, ${ }^{1}$ sensing, ${ }^{2}$ and nanodevices. ${ }^{3}$ These applications are all based on the same underlying principle: oppositely poled surfaces of a ferroelectric material exhibit different chemical and physical properties. Asymmetric surface properties have been observed, for example, in experiments involving chemical etching, ${ }^{4,5}$ thermally induced and photoinduced electron emission, ${ }^{6,7}$ measurements of polarization-dependent surface conductivity, ${ }^{8}$ and solution-based deposition of particles onto ferroelectric substrates. ${ }^{9,10}$ Recently, it has also been found that the adsorption and desorption energetics of various molecules (e.g., alcohols, acetic acid, carbon dioxide, and water) on ferroelectric substrates [e.g., $\mathrm{LiNbO}_{3}, \mathrm{BaTiO}_{3}$, and $\mathrm{Pb}\left(\mathrm{Zr}_{0.52} \mathrm{Ti}_{0.48}\right) \mathrm{O}_{3}$ or PZT] are affected by the substrate polarization. ${ }^{11-18}$

Predicting the effect of polarization reversal on moleculesurface interactions is challenging because there are several factors to consider, including electrostatic effects due to surface polarization charge and screening charge ${ }^{19}$ as well as possible differences in the stoichiometry and arrangement of atoms at oppositely poled surfaces. ${ }^{20,21}$ However, molecular

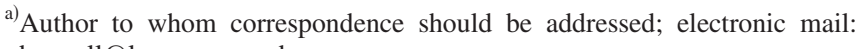
bonnell@1rsm.upenn.edu adsorption on surfaces is often site specific, so one way to address this challenge is to identify the adsorption sites for molecules on a given surface and then to examine how polarization reversal affects the electronic and geometric structure of these sites, for example, through the use of scanning probe microscopy techniques. This article is concerned with the first part of this strategy, identifying the nature of molecular adsorption sites on a ferroelectric material, which in this case is barium titanate $\left(\mathrm{BaTiO}_{3}\right)$. Recent adsorption studies on barium titanate surfaces have indicated that several molecules (carbon dioxide, methanol, ethanol, and 2-fluoroethanol) adsorb at oxygen vacancy sites at room temperature through a precursor-mediated mechanism. ${ }^{15-17}$ In the present work, temperature programmed desorption (TPD) is used to further examine some of these interactions, as well as how they are affected by changes in the crystal surface stoichiometry. The TPD results indicate that oxygen vacancies are the active sites for the room temperature adsorption of methanol and carbon dioxide on $\mathrm{BaTiO}_{3}(001)$.

The formation and electronic structure of bulk and surface oxygen vacancies in $\mathrm{BaTiO}_{3}$ have been studied previously. In general, it has been found that single crystal $\mathrm{BaTiO}_{3}$ can be chemically reduced by annealing in vacuum ( $T$ $=900-1200 \mathrm{~K}$ ), as indicated by a progressive change in the sample color from light yellow to green, and eventually to blue and black. ${ }^{22-26}$ The reduction in $\mathrm{BaTiO}_{3}$ occurs through the loss of oxygen atoms, which makes the material $n$-type and pins the Fermi level near the bottom edge of the conduction band. ${ }^{24}$ It has also been shown that surface oxygen va- 
cancies can be generated by Ar-ion bombardment. ${ }^{22,23}$ These defects can be detected by surface sensitive techniques such as photoelectron spectroscopy. For example, Courths used photoemission, low energy electron diffraction (LEED), and Auger electron spectroscopy (AES) to study the $\mathrm{BaTiO}_{3}(001)$ surface under various conditions. ${ }^{22}$ A stable 1 $\times 1$ structure with a low intensity state in the band gap could be produced by Ar- or O-ion sputtering followed by annealing in ultrahigh vacuum (UHV) to $1100 \mathrm{~K}$. The intensity of the band gap emission state is sensitive to sample annealing conditions: it is greatest when the surface is freshly sputtered or after prolonged vacuum annealing, and it is suppressed upon annealing in $5 \times 10^{-5}$ torr $\mathrm{O}_{2}$ or exposure to $\mathrm{O}_{2}$ at room temperature. Based on these observations, the band gap state is attributed to $\mathrm{Ti}^{3+}-\mathrm{O}$ vacancy complexes on the surface. These defects have also been imaged by scanning tunneling microscopy and spectroscopy (STM/S) on UHV-annealed $\mathrm{BaTiO}_{3}(100){ }^{27}$

The relatively small number of $\mathrm{BaTiO}_{3}$ surface studies have also provided insight into the arrangement of atoms at single crystal surfaces. The perovskite crystal structure of $\mathrm{BaTiO}_{3}$ has two possible bulk $\{001\}$ surface terminations. STM images of $\mathrm{BaTiO}_{3}$ (100) and (001) annealed in vacuum at high temperatures $(T=1270-1570 \mathrm{~K})$ have revealed flat terraces with step edges of unit cell height. ${ }^{25,28,29}$ These observations suggest that one of the two bulk terminations $\left(\mathrm{BaO}\right.$ or $\left.\mathrm{TiO}_{2}\right)$ is stable at high temperatures. There is some evidence in these studies that the $\mathrm{TiO}_{2}$ termination is favored, but it is not entirely clear. Calculations indicate that the thermodynamic stabilities of the two surfaces are comparable. ${ }^{30}$ Other studies have provided evidence for surface reconstructions and the decomposition of $\mathrm{BaTiO}_{3}$ at the crystal surface. For example, core-level photoemission spectroscopy suggests that several $\mathrm{Ba}-\mathrm{O}$ phases exist in the (100) surface layer after annealing in UHV. ${ }^{22,24}$ Ba surface enrichment has also been observed by AES and ion scattering spectroscopy on surfaces annealed to high temperatures with oxygen. ${ }^{29}$ In addition, high resolution electron microscopy shows the presence of separate $\mathrm{Ti}-\mathrm{O}$ and $\mathrm{Ba}-\mathrm{O}$ phases on the surface, as a result of $\mathrm{BaTiO}_{3}$ decomposition under electron irradiation. ${ }^{31}$ Most recently, first principles calculations combined with LEED, atomic force microscopy, and STM have identified the conditions under which Ti-O based reconstructions are stable and those that result in surface decomposition into $\mathrm{Ba}-\mathrm{O}$ and Ti-O phases. ${ }^{28}$ It is clear from these observations that the surface structure of $\mathrm{BaTiO}_{3}$ is highly sensitive to processing conditions.

\section{EXPERIMENTAL PROCEDURES}

A single crystal $\mathrm{BaTiO}_{3}$ sample with $\langle 001\rangle$ orientation was purchased from MTI Corporation. The sample was 5 $\times 5 \times 1 \mathrm{~mm}$, polished on one side and designated as substrate grade by the manufacturer. TPD measurements were performed in a UHV chamber operating at a base pressure of approximately $2 \times 10^{-10}$ torr or lower. The chamber is equipped with a UTI-100C quadrupole mass spectrometer (QMS), a variable leak valve for introducing adsorbate mol- ecules into the system, and instruments for Auger electron spectroscopy and Ar-ion sputtering. The $\mathrm{BaTiO}_{3}$ sample was mounted at the end of a differentially pumped UHV translator. The sample holder was constructed from tantalum foil (0.025 mm thick), and it consisted of a square section to wrap around the back and edges of the sample and four parallel arms extending from the corners. The sample holder was spot welded across two power leads at the end of the translator, and the sample was heated by sending dc current through the sample holder from a computer-controlled power supply. The sample temperature was monitored with a $K$-type thermocouple attached to the back of the crystal with a ceramic adhesive (Aremco Products). A $3 \mathrm{~mm}$ hole was cut into the back of the sample holder to allow for the attachment of the thermocouple. In order to minimize the desorption signal from the support hardware during TPD measurements, the sample was positioned in front of a sample-sized hole in a quartz shield surrounding the QMS analyzer head.

Three different sets of annealing conditions were used to prepare the crystal surface prior to TPD measurements: (1) $T=1000 \mathrm{~K}$ with $8 \times 10^{-8}$ torr oxygen for $30 \mathrm{~min}$; (2) $T$ $=800-950 \mathrm{~K}$ for $4 \mathrm{~h}$ in UHV $\left(p=5 \times 10^{-9}\right.$ torr or lower while annealing); (3) $T=800 \mathrm{~K}$ with $5 \times 10^{-7}$ torr oxygen for $1 \mathrm{~h}$. After each annealing step, TPD measurements were performed separately with methanol (Alfa Aesar, Semiconductor Grade) and carbon dioxide (Matheson, 99.99\%). Additional TPD measurements were performed on the vacuum-annealed surface with ammonia (Matheson, 99.99\%), methylamine (Sigma-Aldrich, $\geqslant 98 \%$ ), and pyridine (Fisher Chemical, Certified ACS). Adsorbate exposure was measured in Langmuir (L) units, where $1 \mathrm{~L}$ is equivalent to $10^{-6}$ torr s. Before leaking the adsorbate molecules into the chamber, the gas supply line was purged repeatedly to minimize contamination. In addition, the methanol and pyridine were purified by several freeze-pump-thaw cycles. In the present study, TPD data were recorded over a temperature range of $300-850 \mathrm{~K}$ while heating the sample at a rate of $1 \mathrm{~K} / \mathrm{s}$.

\section{RESULTS AND DISCUSSION}

Table I lists the species present in the desorption spectra of each probe molecule, along with desorption peak temperatures $\left(T_{p}\right)$. The estimated desorption activation energies $\left(E_{d}\right)$ have been calculated from the Redhead equation, ${ }^{32}$ assuming first-order desorption kinetics and a pre-exponential factor of $10^{13} \mathrm{~s}^{-1}$. Desorption peaks were not observed in the ammonia, methylamine, or pyridine TPD data, indicating that detectable amounts of these molecules did not adsorb on the vacuum-annealed surface at room temperature. The exposures for these three molecules ranged from 10 to $30 \mathrm{~L}$.

The three annealing steps were accompanied by changes in the color of the $\mathrm{BaTiO}_{3}$ sample from light yellow after annealing step 1, to green after step 2, and back to light yellow again after step 3 . We can infer from these color changes that the sample was reduced by annealing in UHV and then partially reoxidized when annealed with $\mathrm{O}_{2}$.

Figure 1 shows TPD spectra obtained from the $\mathrm{BaTiO}_{3}(001)$ surface after each of the three annealing steps 

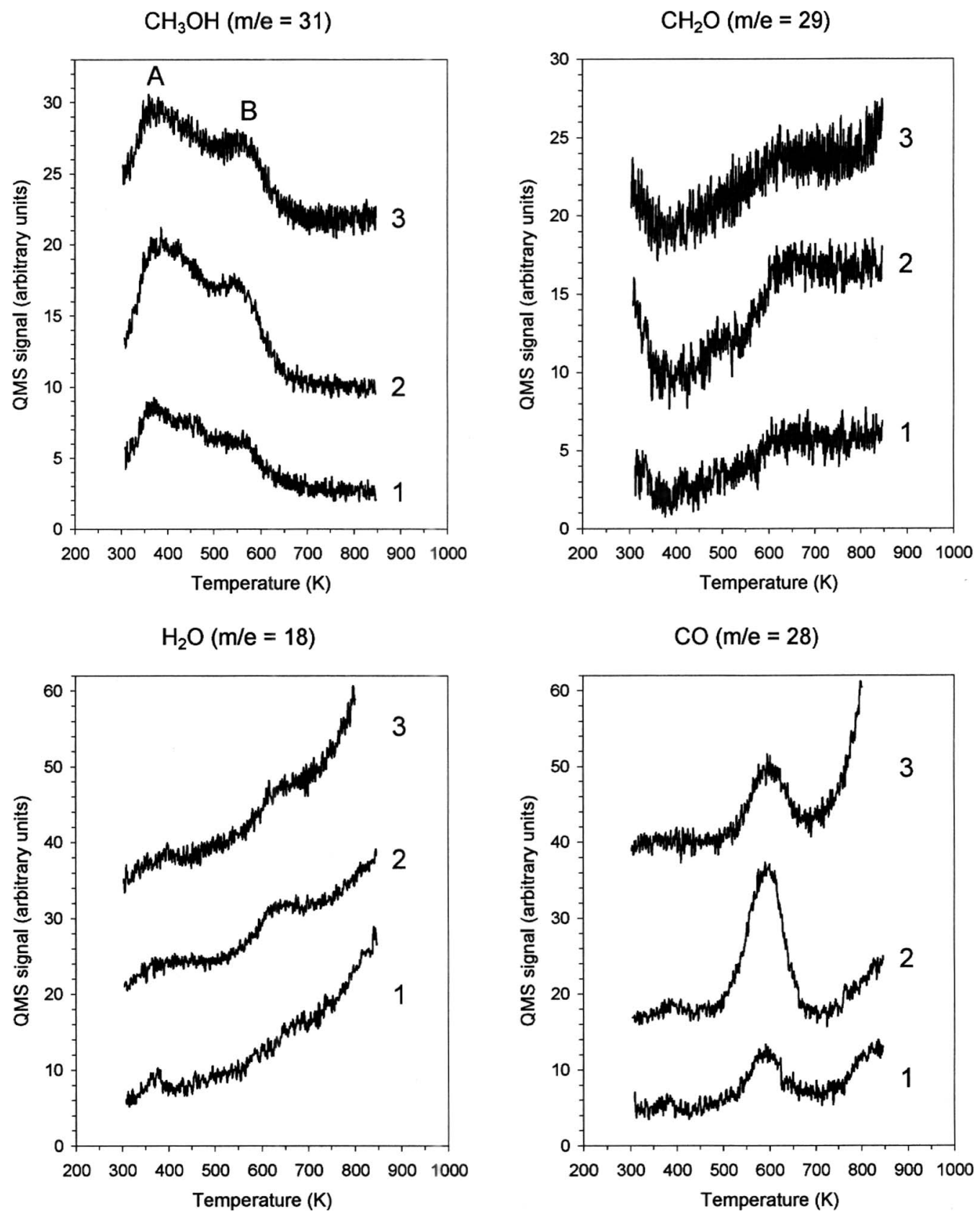

FIG. 1. TPD spectra for $\mathrm{BaTiO}_{3}(001)$ exposed to $25 \mathrm{~L}$ methanol after annealing the crystal under the following conditions: (1) $T=1000 \mathrm{~K}$ with 8 $\times 10^{-8}$ torr $\mathrm{O}_{2}$ for $30 \mathrm{~min}$; (2) $T=800-950 \mathrm{~K}$ in UHV for $4 \mathrm{~h}$; (3) $T=800 \mathrm{~K}$ with $5 \times 10^{-7}$ torr $\mathrm{O}_{2}$ for $1 \mathrm{~h}$. The four charts show the desorption signals of methanol $(m / e=31)$, formaldehyde $(m / e=29)$, water $(m / e=18)$, and carbon monoxide $(m / e=28)$. The formaldehyde desorption curve was calculated by subtracting the contribution of methanol from the total $m / e=29$ signal.

for methanol exposures of $25 \mathrm{~L}$. The desorption signals of $\mathrm{CH}_{3} \mathrm{OH}(m / e=31)$ and three reaction products, which are identified as $\mathrm{CH}_{2} \mathrm{O}(m / e=29), \mathrm{H}_{2} \mathrm{O}(m / e=18)$, and $\mathrm{CO}$ $(m / e=28)$, are plotted separately. On all three surfaces, the $\mathrm{CH}_{3} \mathrm{OH}$ signal produces a broad desorption feature with two major peaks at 380 and $560 \mathrm{~K}$ (labeled $\mathrm{A}$ and $\mathrm{B}$, respectively). However, the amplitude of these peaks is greatest in curve 2, indicating that more methanol adsorbed on the reduced surface as compared with either of the oxidized surfaces. One explanation for this effect is that the reduced surface contains a higher concentration of oxygen vacancies, which serve as adsorption sites for methanol at room temperature. Similar changes in peak amplitude are also observed in the desorption signals of $\mathrm{CH}_{2} \mathrm{O}, \mathrm{H}_{2} \mathrm{O}$, and $\mathrm{CO}$, indicating that oxygen vacancies are also active sites for methanol decomposition.

In previous methanol TPD studies on related oxide surfaces $\left(\mathrm{TiO}_{2}, \mathrm{SrTiO}_{3}\right.$, and polycrystalline $\left.\mathrm{BaTiO}_{3}\right)$, methanol desorption above room temperature, as observed here on $\mathrm{BaTiO}_{3}(001)$, has generally been attributed to the recombinative desorption of methoxide species. ${ }^{14,33-36}$ For example, Kim and Barteau studied methanol decomposition on various 
TABLE I. Summary of TPD products and peak temperatures for various probe molecules on $\mathrm{BaTiO}_{3}(001)$.

\begin{tabular}{llcc}
\hline \hline Probe molecule & Desorbing species & $\begin{array}{c}T_{p} \\
(\mathrm{~K})\end{array}$ & $\begin{array}{c}E_{d} \\
\left(\mathrm{~kJ} \mathrm{~mol}^{-1}\right)\end{array}$ \\
\hline Methanol $\left(\mathrm{CH}_{3} \mathrm{OH}\right)$ & $\mathrm{CH}_{3} \mathrm{OH}$ & 380 & 102 \\
& & 560 & 152 \\
& $\mathrm{CO}$ & 590 & 160 \\
& $\mathrm{CH}_{2} \mathrm{O}$ & 625 & 170 \\
& $\mathrm{H}_{2} \mathrm{O}$ & 625 & 170 \\
& & 360 & 96 \\
Carbon dioxide $\left(\mathrm{CO}_{2}\right)$ & $\mathrm{CO}_{2}$ & 720 & 197 \\
& & $\ldots$ & $\ldots$ \\
Ammonia $\left(\mathrm{NH}_{3}\right)$ & None & $\ldots$ & $\ldots$ \\
Methylamine $\left(\mathrm{CH}_{5} \mathrm{~N}\right)$ & None & $\ldots$ & $\ldots$ \\
Pyridine $\left(\mathrm{C}_{5} \mathrm{H}_{5} \mathrm{~N}\right)$ & None & & \\
\hline \hline
\end{tabular}

single crystal $\mathrm{TiO}_{2}(001)$ surfaces, including the Ar-ion sputtered surface and $\{011\}$ - and $\{114\}$-facetted surfaces, using TPD and XPS. ${ }^{33}$ Low-temperature $(365-375 \mathrm{~K})$ and hightemperature (580-625 K) $\mathrm{CH}_{3} \mathrm{OH}$ desorption peaks (analogous to peaks $\mathrm{A}$ and $\mathrm{B}$ in Fig. 1) were observed on all three surfaces. The low-temperature peak on the Ar-ion sputtered surface was attributed to molecularly adsorbed methanol, but in all other cases both peaks were due to the recombinative desorption of methoxides. Therefore, we believe that methanol adsorbs dissociatively at oxygen vacancy sites on the $\mathrm{BaTiO}_{3}(001)$ surface at room temperature and forms methoxide species. Peaks A and $\mathrm{B}$ in the $\mathrm{CH}_{3} \mathrm{OH}$ desorption signal in Fig. 1 are assigned to the recombinative desorption of methoxides. The desorption of $\mathrm{CH}_{2} \mathrm{O}, \mathrm{H}_{2} \mathrm{O}$, and $\mathrm{CO}$ shown in Fig. 1 is attributed to the decomposition of methoxides at higher temperatures. Peak B may also be a by-product of methoxide decomposition since $\mathrm{C}-\mathrm{H}$ bond cleavage results in additional $\mathrm{H}$ atoms that can react with remaining methoxides to produce methanol. Based on this mechanism one would expect the methanol peak to be at a slightly lower temperature than the formaldehyde peak, which is in agreement with the TPD data. Methoxide decomposition at temperatures similar to those reported here has also been observed on other oxide surfaces, including $\mathrm{TiO}_{2}(001)$ (Ref. $33)$ and $(110),{ }^{35,37}$ reduced $\mathrm{SrTiO}_{3}(100),{ }^{36}$ and reduced $\mathrm{CeO}_{2}(100){ }^{38}$

Figure 2 shows TPD spectra obtained from the $\mathrm{BaTiO}_{3}(001)$ surface with $50 \mathrm{~L}$ exposures of carbon dioxide after the second and third annealing steps only. $\mathrm{CO}_{2}(\mathrm{~m} / e$ =44) was the only species that desorbed from the surface, producing two peaks at 360 and $720 \mathrm{~K}$ (labeled $\mathrm{C}$ and D, respectively). $\mathrm{CO}(m / e=28)$ was also detected by the mass spectrometer, but only as an ionization fragment of the parent $\mathrm{CO}_{2}$ molecule. As indicated by the difference in the areas under the TPD curves, the total amount of $\mathrm{CO}_{2}$ adsorbed on the reduced crystal surface (curve 2) is greater than that adsorbed on the oxidized surface (curve 3). However, the two desorption peaks are affected differently. The magnitude of the leading edge of peak $\mathrm{C}$ is similar for both surfaces, although the peak is broadened slightly to higher temperatures

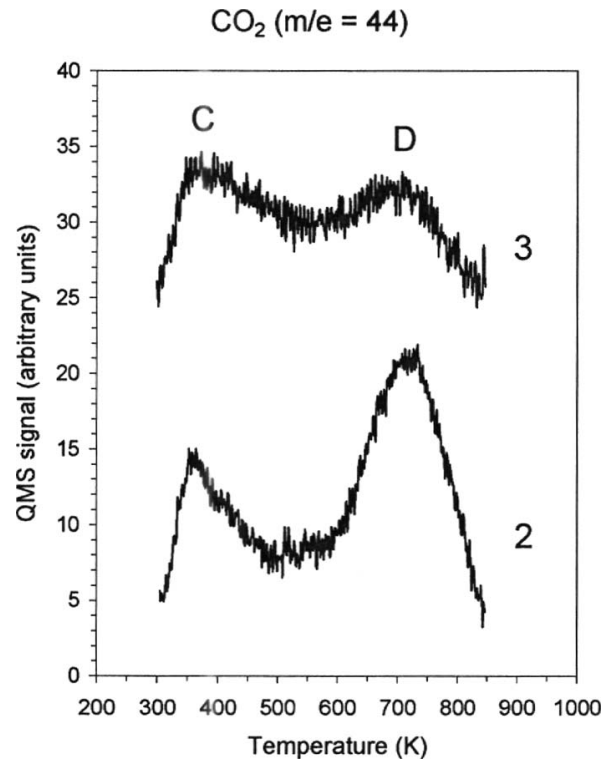

FIG. 2. TPD spectra for $\mathrm{BaTiO}_{3}(001)$ exposed to $50 \mathrm{~L}$ carbon dioxide after annealing the crystal under the following conditions: (2) $T=800-950 \mathrm{~K}$ in UHV for $4 \mathrm{~h}$; (3) $T=800 \mathrm{~K}$ with $5 \times 10^{-7}$ torr $\mathrm{O}_{2}$ for $1 \mathrm{~h}$. A linear background subtraction was applied to these desorption curves.

on the oxygen-annealed surface. In contrast, peak D, which is the dominant peak on the reduced surface, is significantly smaller on the oxidized surface. This suggests that only the high-temperature peak should be attributed to $\mathrm{CO}_{2}$ adsorbed at oxygen vacancies. The low-temperature peak may be due to $\mathrm{CO}_{2}$ adsorbed at step edges or stoichiometric sites.

TPD measurements on single crystal $\mathrm{TiO}_{2}(110)$ (Refs. 39-41) and $\mathrm{SrTiO}_{3}(100)$ (Ref. 42) indicate that $\mathrm{CO}_{2}$ interacts weakly with these surfaces, desorbing well below $300 \mathrm{~K}$ from both five-coordinate $\mathrm{Ti}^{4+}$ and oxygen vacancy sites on $\mathrm{TiO}_{2}$ and from stoichiometric $\mathrm{Ti}^{4+}$ sites on $\mathrm{SrTiO}_{3}$. Higher desorption temperatures have been observed, however, in TPD studies performed from room temperature on single crystal $\mathrm{TiO}_{2}(110)$ (Ref. 43) and the $\{011\}$-facetted surface of $\mathrm{TiO}_{2}(001){ }^{44}$ Interestingly, in these two cases (Refs. 43 and 44) the $\mathrm{CO}_{2}$ desorption activation energies were 96 and $92 \mathrm{~kJ} / \mathrm{mol}$, respectively, which is in agreement with the desorption energy associated with the low-temperature $\mathrm{CO}_{2}$ peak on $\mathrm{BaTiO}_{3}(001)$ (see Table I). This agreement may be a coincidence, or it may indicate that $\mathrm{CO}_{2}$ can have a similar adsorption mechanism on stoichiometric $\mathrm{TiO}_{2}$ and $\mathrm{BaTiO}_{3}$ surfaces at room temperature. $\left[\mathrm{CO}_{2}\right.$ can adsorb on stoichiometric oxide surfaces at cation or anion sites in a variety of bonding configurations, but theoretical studies have indicated that while $\mathrm{CO}_{2}$ adsorbs preferentially at cation sites on various $\mathrm{TiO}_{2}$ surfaces, ${ }^{4,46}$ it prefers oxygen anion sites on $\mathrm{BaO}(100),{ }^{47} \mathrm{BaTiO}_{3}(001),{ }^{48}$ and both $\mathrm{SrO}-$ and $\mathrm{TiO}_{2}$-terminated $\mathrm{SrTiO}_{3}(001)$ surfaces. ${ }^{49}$ ] In addition, a dramatic increase in the chemisorption energy of $\mathrm{CO}_{2}$ on $\mathrm{SrTiO}_{3}(100)$ is observed at oxygen vacancy sites induced by Ar-ion sputtering, resulting in a TPD peak at $650 \mathrm{~K} .{ }^{42}$ This is consistent with the assignment of peak D in Fig. 2 to $\mathrm{CO}_{2}$ adsorbed at oxygen vacancies. (It should be noted that $\mathrm{CO}$ 
was also detected in $\mathrm{CO}_{2} \mathrm{TPD}$ on the reduced $\mathrm{SrTiO}_{3}$ surface ${ }^{42}$ but has not been detected presently on $\mathrm{BaTiO}_{3}$.) It is also interesting to compare the desorption energies corresponding to peaks $\mathrm{C}$ and $\mathrm{D}$ in Fig. 2 with chemisorption energies obtained by density functional theory (DFT) calculations for $\mathrm{CO}_{2}$ adsorbed on $\mathrm{SrTiO}_{3}(001){ }^{49}$ DFT calculations indicate values of $\sim 1 \mathrm{eV}(96 \mathrm{~kJ} / \mathrm{mol})$ for $\mathrm{CO}_{2}$ adsorbed at oxygen surface sites and $2.1 \mathrm{eV}(203 \mathrm{~kJ} / \mathrm{mol})$ for oxygen vacancy sites, which are in agreement with the corresponding values in Table I. This agreement with theory supports the assignment of the low- and high-temperature $\mathrm{CO}_{2}$ desorption peaks for $\mathrm{BaTiO}_{3}(001)$ to $\mathrm{CO}_{2}$ adsorbed at oxygen and oxygen vacancy sites, respectively.

\section{CONCLUSION}

The interactions of various molecules with the single crystal $\mathrm{BaTiO}_{3}(001)$ surface have been characterized by temperature programmed desorption. The surface was exposed to each TPD probe molecule at room temperature after annealing the crystal under oxidizing or reducing conditions to change the concentration of surface oxygen vacancy defects. The TPD spectra of $\mathrm{NH}_{3}, \mathrm{CH}_{5} \mathrm{~N}$, and $\mathrm{C}_{5} \mathrm{H}_{5} \mathrm{~N}$ were flat, indicating that detectable amounts of these molecules did not adsorb at room temperature. Methanol and carbon dioxide both produced repeatable TPD spectra, which showed multiple desorption states and reaction products for methanol and low- and high-temperature desorption states for $\mathrm{CO}_{2}$. The amount of adsorbed methanol was greater for the reduced surface than for the oxidized surfaces, indicating that methanol adsorbs and reacts at oxygen vacancies. For carbon dioxide, only the high-temperature peak showed an increase in magnitude on the reduced surface, indicating that the high-temperature state corresponds to $\mathrm{CO}_{2}$ adsorbed at oxygen vacancies. The low-temperature peak may be attributed to $\mathrm{CO}_{2}$ adsorbed at oxygen anion sites or other nonvacancy defects such as step edges.

This TPD study confirms earlier indications that methanol and $\mathrm{CO}_{2}$ adsorb on $\mathrm{BaTiO}_{3}$ surfaces at oxygen vacancy sites, and it indicates the temperature range over which these adsorption interactions are stable. The information contained in Table I may be useful in guiding future studies involving adsorption on $\mathrm{BaTiO}_{3}$ or similar materials. In addition, the correct identification of molecular adsorption sites is an important component of the current effort to understand the mechanism by which polarization affects the surface chemical reactivity of barium titanate and other ferroelectric materials.

\section{ACKNOWLEDGMENTS}

The authors gratefully acknowledge the support in this work by the NSF MRSEC program (DMR05-200-20) and the use of facilities supported by the Nano/Bio Interface Center. Support from the NSF IGERT program (DGE0221664) is acknowledged by J.G.

\footnotetext{
${ }^{1}$ Y. Inoue and Y. Watanabe, Catal. Today 16, 487 (1993).

${ }^{2}$ Y. Inoue, K. Sato, and O. Hayashi, J. Chem. Soc., Faraday Trans. 1 83,
}

3061 (1987).

${ }^{3}$ S. V. Kalinin, D. A. Bonnell, T. Alvarez, X. Lei, Z. Hu, R. Shao, and J. H. Ferris, Adv. Mater. (Weinheim, Ger.) 16, 795 (2004).

${ }^{4}$ J. A. Hooton and W. J. Merz, Phys. Rev. 98, 409 (1955).

${ }^{5}$ K. Nassau, H. J. Levinstein, and G. M. Loiacono, J. Phys. Chem. Solids 27, 983 (1966).

${ }^{6}$ B. Rosenblum, P. Bräunlich, and J. P. Carrico, Appl. Phys. Lett. 25, 17 (1974).

${ }^{7}$ W.-C. Yang, B. J. Rodriguez, A. Gruverman, and R. J. Nemanich, Appl. Phys. Lett. 85, 2316 (2004).

${ }^{8}$ Y. Watanabe, M. Okano, and A. Masuda, Phys. Rev. Lett. 86, 332 (2001).

${ }^{9}$ J. L. Giocondi and G. S. Rohrer, J. Phys. Chem. B 105, 8275 (2001).

${ }^{10}$ S. Habicht, R. J. Nemanich, and A. Gruverman, Nanotechnology 19, 495303 (2008).

${ }^{11}$ Y. Yun and E. I. Altman, J. Am. Chem. Soc. 129, 15684 (2007).

${ }^{12}$ Y. Yun, L. Kampschulte, M. Li, D. Liao, and E. I. Altman, J. Phys. Chem. C 111, 13951 (2007).

${ }^{13}$ A. M. Kolpak, I. Grinberg, and A. M. Rappe, Phys. Rev. Lett. 98, 166101 (2007).

${ }^{14}$ S. C. Bharath, K. R. Pimputkar, A. M. Pronschinske, and T. P. Pearl, Appl. Surf. Sci. 254, 2048 (2008).

${ }^{15}$ D. Li, M. H. Zhao, J. Garra, A. M. Kolpak, A. M. Rappe, D. A. Bonnell, and J. M. Vohs, Nature Mater. 7, 473 (2008)

${ }^{16}$ M. H. Zhao, D. A. Bonnell, and J. M. Vohs, Surf. Sci. 602, 2849 (2008).

${ }^{17}$ M. H. Zhao, D. A. Bonnell, and J. M. Vohs, Surf. Sci. 603, 284 (2009).

${ }^{18}$ J. Garra, J. M. Vohs, and D. A. Bonnell, Surf. Sci. 603, 1106 (2009).

${ }^{19}$ S. V. Kalinin and D. A. Bonnell, Phys. Rev. B 63, 125411 (2001).

${ }^{20}$ Y. Yun, M. Li, D. Liao, L. Kampschulte, and E. I. Altman, Surf. Sci. 601, 4636 (2007).

${ }^{21}$ S. V. Levchenko and A. M. Rappe, Phys. Rev. Lett. 100, 256101 (2008).

${ }^{22}$ R. Courths, Phys. Status Solidi B 100, 135 (1980).

${ }^{23}$ B. Cord and R. Courths, Surf. Sci. 152-153, 1141 (1985).

${ }^{24}$ L. T. Hudson, R. L. Kurtz, S. W. Robey, D. Temple, and R. L. Stockbauer, Phys. Rev. B 47, 1174 (1993).

${ }^{25}$ T. Shimizu, H. Bando, Y. Aiura, Y. Haruyama, K. Oka, and Y. Nishihara, Jpn. J. Appl. Phys., Part 2 34, L1305 (1995).

${ }^{26}$ S. M. Mukhopadhyay and T. S. Chen, J. Mater. Res. 10, 1502 (1995).

${ }^{27}$ H. Bando, T. Shimitzu, Y. Aiura, Y. Haruyama, K. Oka, and Y. Nishihara, J. Vac. Sci. Technol. B 14, 1060 (1996).

${ }^{28}$ A. M. Kolpak, D. Li, R. Shao, A. M. Rappe, and D. A. Bonnell, Phys. Rev. Lett. 101, 036102 (2008).

${ }^{29}$ Ch. Hagendorf, K.-M. Schindler, T. Doege, and H. Neddermeyer, Appl. Surf. Sci. 142, 106 (1999).

${ }^{30}$ J. Padilla and D. Vanderbilt, Phys. Rev. B 56, 1625 (1997).

${ }^{31}$ L. A. Bursill, J. Peng, and X. Fan, Ferroelectrics 97, 71 (1989).

${ }^{32}$ P. A. Redhead, Vacuum 12, 203 (1962).

${ }^{33}$ K. S. Kim and M. A. Barteau, Surf. Sci. 223, 13 (1989).

${ }^{34}$ E. Román, F. J. Bustillo, and J. L. de Segovia, Vacuum 41, 40 (1990).

${ }^{35}$ M. A. Henderson, S. Otero-Tapia, and M. E. Castro, Faraday Discuss. 114, 313 (1999).

${ }^{36}$ L.-Q. Wang, K. F. Ferris, S. Azad, and M. H. Engelhard, J. Phys. Chem. B 109, 4507 (2005).

${ }^{37}$ E. Farfan-Arribas and R. J. Madix, Surf. Sci. 544, 241 (2003).

${ }^{38}$ R. M. Ferrizz, G. S. Wong, T. Egami, and J. M. Vohs, Langmuir 17, 2464 (2001).

${ }^{39}$ S. Funk, B. Hokkanen, E. Johnson, and U. Burghaus, Chem. Phys. Lett. 422, 461 (2006).

${ }^{40}$ M. A. Henderson, Surf. Sci. 400, 203 (1998).

${ }^{41}$ T. L. Thompson, O. Diwald, and J. T. Yates, J. Phys. Chem. B 107, 11700 (2003).

${ }^{42}$ S. Azad, M. H. Engelhard, and L.-Q. Wang, J. Phys. Chem. B 109, 10327 (2005).

${ }^{43}$ W. Göpel, G. Rocker, and R. Feierabend, Phys. Rev. B 28, 3427 (1983).

${ }^{44}$ J. N. Wilson, S. D. Senanayake, and H. Idriss, Surf. Sci. 562, L231 (2004).

${ }^{45}$ A. Markovits, A. Fahmi, and C. Minot, J. Mol. Struct.: THEOCHEM 371, 219 (1996).

${ }^{46}$ L.-F. Liao, C.-F. Lien, D.-L. Shieh, M.-T. Chen, and J.-L. Lin, J. Phys. Chem. B 106, 11240 (2002).

${ }^{47}$ M. Tutuianu, O. R. Inderwildi, W. G. Bessler, and J. Warnatz, J. Phys. Chem. B 110, 17484 (2006).

${ }^{48}$ A. M. Kolpak and A. M. Rappe, private communication (2004).

${ }^{49}$ J. D. Baniecki et al., Phys. Rev. B 78, 195415 (2008). 